\title{
New-onset diabetes after transplantation in tacrolimus-treated, living kidney transplantation: long-term impact and utility of the pre-transplant OGTT
}

\author{
Shoichi Iida $\cdot$ Hideki Ishida $\cdot$ Tadahiko Tokumoto $\cdot$ Kazuya Omoto $\cdot$ \\ Hiroki Shirakawa $\cdot$ Tomokazu Shimizu $\cdot$ Hiroyuki Amano $\cdot$ Kiyoshi Setoguchi • \\ Taiji Nozaki $\cdot$ Daisuke Toki $\cdot$ Daisuke Tokita $\cdot$ Kazunari Tanabe
}

Received: 11 November 2009/Accepted: 29 January 2010/Published online: 19 February 2010

(C) The Author(s) 2010. This article is published with open access at Springerlink.com

\begin{abstract}
Background To evaluate the role of the oral glucose tolerance test (OGTT) before transplantation and to examine the risk factors for new-onset diabetes after transplantation (NODAT) during long-term follow-up of renal transplant recipients receiving FK-based therapy.

Methods The study evaluated 378 patients pretransplantation using the OGTT and assigned them to one of three groups: Group 1, normal pattern; Group 2, impaired fasting glucose (IFG)/impaired glucose tolerance (IGT) pattern (IFG/IGT); and Group 3, DM pattern.

Results Although the incidence of NODAT was higher in Group 3 than in groups 1 and 2, no significant difference was found between the three groups with regard to graft survival during long-term follow-up.
\end{abstract}

S. Iida $\cdot$ H. Ishida $\cdot$ T. Tokumoto $\cdot$ K. Omoto .

H. Shirakawa - T. Shimizu - H. Amano - K. Setoguchi ·

T. Nozaki · D. Toki · D. Tokita · K. Tanabe

Section of Renal Transplantation/Renovascular Surgery,

Tokyo Women's Medical University, Tokyo, Japan

S. Iida $(\bowtie) \cdot H$. Ishida $\cdot$ T. Tokumoto $\cdot$ K. Omoto ·

H. Shirakawa - T. Shimizu - H. Amano - K. Setoguchi ·

T. Nozaki $\cdot$ D. Toki $\cdot$ D. Tokita $\cdot$ K. Tanabe

The Department of Urology, Kidney Center, Tokyo

Women's Medical University, 8-1 Kawata-cho,

Shinjuku-ku, Tokyo 162-8666, Japan

e-mail: sho.i@f4.dion.ne.jp
Multivariate analysis showed that only a family history of diabetes was a significant factor determining NODAT progression.

Conclusions Impaired glucose tolerance appears to be a threshold influencing NODAT; however, it was not a significant factor in graft survival. Careful monitoring and management based on the result of the pre-transplantation OGTT appear to prevent the deterioration of impaired glucose tolerance in renal transplant recipients receiving FK-based therapy, even when a pre-operative OGTT shows impaired glycemic control.

Keywords NODAT - FK506 ·

Renal transplantation · Pre-transplantation oral glucose tolerance test

$\begin{array}{ll}\text { Abbreviations } & \\ \text { AHR } & \text { Acute humoral rejection } \\ \text { AZ } & \text { Azathioprine } \\ \text { BMI } & \text { Body mass index } \\ \text { DFPP } & \text { Double-filtration plasmapheresis } \\ \text { DM } & \text { Diabetes mellitus } \\ \text { FBG } & \text { Fasting blood glucose } \\ \text { FK } & \text { FK506 } \\ \text { HbA1c } & \text { Blood hemoglobin A1c } \\ \text { IFG } & \text { Impaired fasting glucose } \\ \text { IGT } & \text { Impaired glucose tolerance } \\ \text { MMF } & \text { Mycophenolate mofetil } \\ \text { MP } & \text { Methylprednisolone } \\ \text { MZ } & \text { Mizoribine }\end{array}$




$\begin{array}{ll}\text { NODAT } & \begin{array}{l}\text { New-onset diabetes after } \\ \text { transplantation }\end{array} \\ \text { OGTT } & \text { Oral glucose tolerance test } \\ \text { RBG } & \text { Random blood glucose } \\ \text { s-Cr } & \text { Serum creatinine } \\ \text { Kw/Bw ratio } & \text { Kidney weight-to-recipient body } \\ & \text { weight ratio }\end{array}$

\section{Introduction}

New-onset diabetes after transplantation (NODAT) is a form of diabetes for which onset or first recognition occurs following organ or cellular transplantation $[1,2]$. For many years, NODAT has been recognized as a complication that may contribute to cardiovascular mortality and graft failure after transplantation [3, 4], although its importance has been underestimated.

Studies have shown that the cumulative incidence of this condition in transplant recipients is up to 10 -fold higher than that reported in the non-transplanted population [4-9]. NODAT may develop as a result of impairment of insulin secretion and/or increased insulin resistance. Patients with impaired $\beta$-cell function prior to transplantation are at risk of developing NODAT during treatment with calcineurin inhibitors $[10,11]$. However, insulin resistance has been suggested as an additional mechanism for the development of NODAT during maintenance therapy with tacrolimus (FK506; FK) of renal transplant recipients [5]. Coadministration of steroids may well be the cause of this increased insulin resistance $[10,12]$.

The mechanism underlying the development of NODAT in patients receiving FK treatment remains unclear [4]. In addition to the effects of the drug, the underlying disease itself may increase the risk of developing diabetes mellitus (DM) [13-15].

Various studies have reported tacrolimus (FK506; FK) therapy to be a risk factor for new-onset diabetes after transplantation (NODAT). However, no optimal pre-transplantation monitoring system to predict NODAT has emerged. In this study, we evaluated the value of administering the oral glucose tolerance test (OGTT) before transplantation to predict NODAT in living-related renal transplant recipients receiving FK-based therapy. In addition, the possible effect of FK on the development of IGT was investigated.

\section{Materials and methods}

Patients

We conducted a retrospective analysis of consecutive adult patients who were transplanted with a living kidney at our institution in the period from April 2001 to March 2006. We enrolled 800 Japanese patients who met the following criteria: (1) aged 19 or older; (2) on the waiting list for renal transplantation; (3) with no known history of clinical diabetes; and (4) with no history of treatment with steroids or other immunosuppressive agents. All the study procedures were approved by the Institutional Review Board of Tokyo Women's Medical University.

Of the 800 enrolled patients, 378 received FK-based immunosuppressive therapy, which included FK, azathioprine (AZ, Azanine ${ }^{\circledR}$; Tanabe Pharmacy, Tokyo, Japan), mycophenolate mofetil (MMF, Cell$\mathrm{Cept}^{\circledR}$; Roche, Nutley, NJ), and steroids. The remaining 422 who received cyclosporine-based therapy were excluded from this study because of insufficient pre-transplant OGTT. Thus, 378 patients whose follow-up period was $>24$ months were the subjects of the present study. The median age of the patients was 37.5 years (range, 19.7-51.2 years), and the study population comprised 137 women and 241 men. The primary renal disease was not related to DM in any of the enrolled patients. The baseline characteristics of the 378 patients are shown in Table 1.

\section{Immunosuppressive protocol}

All of the patients received FK (Prograf ${ }^{\circledR}$; Astellas Fujisawa, Osaka, Japan) immunosuppressive therapy both before and after transplantation. The immunosuppressive regimen has been described previously $[16,17]$. In brief, the induction phase of immunosuppression was initiated 7 days before transplantation, and the target trough level of FK was 8-12 ng/ ml. Post transplantation, the target FK trough levels in all the patients were $8-12 \mathrm{ng} / \mathrm{ml}$ from Day 1 to 30 and 7 to $9 \mathrm{ng} / \mathrm{ml}$ from Day 30 to 90 ; thereafter, the drug dosage was adjusted gradually to maintain a trough level of the drug of 4-6 ng/ml. Methylprednisolone (MP, Medorol ${ }^{\circledR}$; Pfizer, Tokyo, Japan) treatment was also initiated 7 days before transplantation. MP was administered at 250 or $500 \mathrm{mg}$ on 
Table 1 Patient characteristics a Statistical comparison of groups was performed using one-way ANOVA

${ }^{\mathrm{b}}$ Data are expressed as the means \pm standard deviation

c There were no statistically significant differences in the clinical characteristics of the patients between the groups, except for age $(P=0.026)$

d Kidney weight-torecipient body weight ratio

\begin{tabular}{|c|c|c|c|c|}
\hline Groups & $\begin{array}{l}\text { Group 1 } \\
(n=248, \\
65.6 \%)\end{array}$ & $\begin{array}{l}\text { Group 2 } \\
(n=115, \\
30.4 \%)\end{array}$ & $\begin{array}{l}\text { Group } 3 \\
(n=15, \\
4.0 \%)\end{array}$ & $P$ value $^{\mathrm{a}}$ \\
\hline \multicolumn{5}{|l|}{ Recipient } \\
\hline Gender & & & & 0.075 \\
\hline Men & $148(59.7 \%)$ & $83(72 \%)$ & $10(66.7 \%)$ & \\
\hline Women & $100(40.3 \%)$ & $32(27.8 \%)$ & $5(33.3 \%)$ & \\
\hline Age (year) & $36.4 \pm 11.3^{\mathrm{b}}$ & $39.6 \pm 11.2$ & $40.3 \pm 14.1$ & $0.026^{\mathrm{c}}$ \\
\hline Body mass index $\left(\mathrm{kg} / \mathrm{m}^{2}\right)$ & $20.5 \pm 2.8$ & $21.0 \pm 2.9$ & $21.2 \pm 2.8$ & 0.325 \\
\hline Duration of hemodialysis (mo) & $27[14-56]$ & 35 [13-83] & $29[15-56]$ & 0.758 \\
\hline $\mathrm{Kw} / \mathrm{Bw} \mathrm{ratio}^{\mathrm{d}}$ & $3.24 \pm 0.97$ & $3.13 \pm 1.03$ & $3.19 \pm 0.82$ & 0.641 \\
\hline \multicolumn{5}{|l|}{ Cause of end-stage renal disease } \\
\hline Chronic glomerulonephritis & $103(41.5 \%)$ & $53(46.1 \%)$ & $5(33.3 \%)$ & \\
\hline IgA nephropathy & $61(24.6 \%)$ & $24(20.9 \%)$ & $4(26.7 \%)$ & \\
\hline Aplastic kidney & $7(2.8 \%)$ & & $1(6.7 \%)$ & \\
\hline Focal sclerosing glomerulopathy & $12(4.8 \%)$ & $5(4.3 \%)$ & & \\
\hline $\begin{array}{l}\text { Membrano proliferative } \\
\text { glomerulonephritis }\end{array}$ & $4(1.6 \%)$ & $3(2.6 \%)$ & & \\
\hline Cystic kidney & $9(3.6 \%)$ & $1(0.9 \%)$ & $1(6.7 \%)$ & \\
\hline Alport's syndrome & $2(0.8 \%)$ & $2(1.7 \%)$ & & \\
\hline Purpura nephritis & $5(2.0 \%)$ & $1(0.9 \%)$ & & \\
\hline $\begin{array}{l}\text { Rapidly progressive } \\
\text { glomerulonephritis }\end{array}$ & $7(2.8 \%)$ & $3(2.6 \%)$ & & \\
\hline Nephritis SLE & $3(1.2 \%)$ & & & \\
\hline \multicolumn{5}{|l|}{ Donor } \\
\hline Gender & & & & 0.169 \\
\hline Men & $80(32.3 \%)$ & $46(40.0 \%)$ & $3(20.0 \%)$ & \\
\hline Women & $168(67.7 \%)$ & $69(60.0 \%)$ & $12(80.0 \%)$ & \\
\hline Age & $55.8 \pm 10.0$ & $55.0 \pm 10.0$ & $56.0 \pm 8.7$ & 0.779 \\
\hline$\geq 60$ year & $93(37.5 \%)$ & $39(33.9 \%)$ & $6(40.0 \%)$ & 0.722 \\
\hline
\end{tabular}

Day 0; thereafter, all the patients received $16 \mathrm{mg} /$ day in the first 4 weeks post-transplantation. The MP dosage was then tapered to $8 \mathrm{mg} / \mathrm{day}$ at 3 months post transplantation. Additional usage of AZ, MMF, or mizoribine (MZ, Bredinin ${ }^{\circledR}$; Asahikasei Pharmacy, Tokyo, Japan) was allowed. Induction with anti-IL-2 receptor antibody (Basiliximab; $20 \mathrm{mg}$ on Days 0 and 4) was used in ABO-incompatible renal transplantation. In addition, to remove anti-A and/or anti-B antibodies in cases of ABO-incompatible renal transplantation, the recipients received three or four sessions of double-filtration plasmapheresis (DFPP). Splenectomy was also performed on these patients.

\section{Pre-transplantation OGTT}

According to the 2003 International Consensus Guidelines [18], the patients were divided into three groups based on their pre-transplantation patterns of glucose tolerance, as assessed by the OGTT, i.e., normal, IFG/IGT, and DM. The OGTT, which involved the administration of $75 \mathrm{~g}$ of glucose, was performed 2 weeks before transplantation. The test was performed in the morning on patients who had fasted overnight, and the fasting blood glucose levels at 0,30 , 60 , and $120 \mathrm{~min}$ after oral glucose load were measured, before the start of oral treatment of the patients with FK (given twice daily at $0.10 \mathrm{mg} / \mathrm{kg}$ body weight). 
The normal pattern was defined as a fasting blood glucose level $<100 \mathrm{mg} / \mathrm{dl}$ or a 2 -h glucose level $<140 \mathrm{mg} / \mathrm{dl}$ in the OGTT. The IFG/IGT pattern was defined as a fasting blood glucose level between 100 and $125 \mathrm{mg} / \mathrm{dl}$ or a 2 -h glucose level between $140 \mathrm{mg} / \mathrm{dl}$ and $199 \mathrm{mg} / \mathrm{dl}$ in the OGTT. The DM pattern was defined as a fasting blood glucose level of $\geq 126 \mathrm{mg} / \mathrm{dl}$ or a 2 -h serum glucose level of $\geq 200 \mathrm{mg} / \mathrm{dl}$ during the OGTT.

\section{Post-transplantation monitoring}

The following laboratory tests were performed twice weekly for 3 months, then weekly for 3 months, and twice monthly for 1 year: $\mathrm{CBC}$, differential and platelet counts, serum creatinine ( $\mathrm{s}-\mathrm{Cr}$ ), serum electrolytes, urinary protein from a spot urine sample, serum HbA1c, fasting blood sugar, and FK trough level.

Diagnosis and treatment of rejection

All rejections were confirmed by graft biopsy. Biopsies were performed according to clinical indications when the serum creatinine level increased by $0.3 \mathrm{mg} / \mathrm{dl}$ above baseline, and the patient had symptoms such as oliguria or fever. Cellular rejection was treated with methylprednisolone (MP) $500 \mathrm{mg} /$ day intravenously for 2 days followed by a tapered regimen. When rejection was resistant to MP, it was treated with OKT3 (Orthoclone ${ }^{\circledR}$, Ortho-Biotech, Tokyo, Japan) $5 \mathrm{mg} /$ day for 7 days. The criteria for acute humoral rejection (AHR) were in accordance with those proposed by Banff criteria [19]. AHR was treated with OKT3 and three sessions of plasmapheresis. In addition, we performed protocol biopsies in all patients within 6 months after transplantation. Subclinical rejection was diagnosed when there was histological evidence of rejection according to the 1997 Banff criteria [19] in the absence of serum creatinine elevation. Subclinical rejection, including borderline changes, was treated with MP $500 \mathrm{mg} /$ day for 2 days followed by tapering. We did not perform protocol biopsies between 1990 and 1999.

Diagnosis and treatment of NODAT

For the purposes of this study, NODAT was defined as a morning fasting blood glucose (FBG) level of $\geq 126 \mathrm{mg} / \mathrm{dl}$ or a random blood glucose (RBG) level of $\geq 200 \mathrm{mg} / \mathrm{dl}$ on more than one occasion or a 2 -h plasma glucose level of $\geq 200 \mathrm{mg} / \mathrm{dl}$ in the OGTT [18]. During hospitalization, the morning glucose values were excluded as a criterion for diagnosing type 2 diabetes in patients with metabolic decompensation (ketoacidosis, hyperosmolar coma), patients with severe illness requiring admission to the intensive care unit, and patients who received intravenous dextrose.

Transient and permanent NODAT were defined as follows. Patients who had required transient antidiabetic therapy more than once during the follow-up period were defined as transient NODAT, and patients who developed permanent antiglycemic agent-dependent DM were defined as permanent NODAT.

Patients with fasting blood glucose levels $\geq 126 \mathrm{mg} / \mathrm{dl}$ were initially placed on dietary restriction; those who were refractory to diet control alone were started on oral hypoglycemic agents, and patients who showed an inadequate response to oral hypoglycemic agents were started on subcutaneous insulin.

Statistical analysis

Statistical analyses were performed with the SAS system (version 9.1; SAS Institute, Cary, NC). Data are presented as means \pm standard deviations (SD) and medians with interquartile ranges or frequencies. Oneway analysis of variance (ANOVA) was used to compare the three groups for normally distributed continuous variables, and the Kruskal-Wallis test was used for other variables. The $\chi^{2}$-test was used to compare nominally scaled variables. The cumulative probabilities for graft and patient survival were estimated by the Kaplan-Meier method. To evaluate the results of the 75-g OGTT in relation to the subsequent new onset of diabetes, a logistic regression model was used. A multivariate analysis for the risk factors influencing permanent NODAT was performed using the Cox proportional hazards model with stepwise selection. A two-tailed $P$ value $<0.05$ was considered to indicate a statistically significant difference.

\section{Results}

Patients' characteristics

The study was completed for all the patients and comprised 378 living-related kidney transplantations. 
The patients were divided into three groups according to the patterns of glucose tolerance assessed in the pre-transplantation OGTT. Of the total patient population, $248(65.6 \%)$ patients showed the normal pattern (Group 1), 115 (30.4\%) showed the IFG or IGT pattern (IFG/IGT; Group 2), and 15 (4.0\%) showed the DM pattern (Group 3).

Four percent of patients were identified at baseline as having DM by pre-transplant OGTT instead of having no known history of clinical diabetes and no history of treatment with steroids or other immunosuppressive agents. Such patients cannot strictly be included in the new-onset diabetes after transplantation (NODAT) cohort; however, to investigate the long-term results, we included these patients in this study for comparison.

There were no statistically significant differences in the clinical characteristics of the patients among the groups $(P>0.05)$, with the exception of age $(P<0.05)$.

Sequential changes in serum creatinine, urinary protein, fasting blood glucose, and blood hemoglobin A1c after transplantation

Figure 1 shows the sequential changes for each group in the following: (a) serum creatinine (s-Cr) $(\mathrm{mg} / \mathrm{dL})$; (b) urinary protein (g/day); (c) fasting blood glucose (mg/dl); and (d) blood hemoglobin A1c (HbAlc; \%). The mean levels of s-Cr and urinary protein were maintained during the follow-up period for all the groups. However, the fasting blood glucose levels in Groups 2 and 3 increased gradually, and that of Group 3 was $>26 \mathrm{mg} / \mathrm{dl}$ for the last 3 years. Although the HbA1c levels were higher $(>6.5 \%)$ for the last 2 years in Group 3, there were no statistically significant differences between the three groups $(P>0.05)$. In addition, post-operative FK dose, FK trough level, and total dosage of steroids did not differ significantly between the three groups after renal transplantation and throughout the follow-up period (data not shown).

Patient and graft survival rates

As shown in Fig. 2a, b, the overall 10-year survival rate of the patients was $98.4 \%$, and there were no statistically significant differences between the three groups $(P>0.05)$. The Kaplan-Meier 10-year allograft survival estimates for all groups showed that the 5-year graft survival rate was $91.2 \%$ in Group 1, $92.5 \%$ in Group 2, and $79.4 \%$ in Group 3. The 10year graft survival rate was $78.8 \%$ in Group $1,74.9 \%$ in Group 2, and $79.4 \%$ in Group 3. Although the 5-year graft survival rate was lower in Group 3 than in Groups 1 and 2, there were no statistically significant differences in the 10-year graft survival rates between the three groups $(P>0.05)$.

Long-term outcomes for transplanted patients

Pathologic diagnosis of each patient was carried out using a sample of the protocol or/and episodic biopsy within 6 months of renal transplantation, based on the Banff criteria (1997). Chronic rejection was observed in 83/248 (33.5\%) recipients in Group 1. Acute rejection, including subclinical rejection, was observed in $52 / 248(21.0 \%)$ recipients. The numbers (percentages) of patients in Groups 2 and 3 who experienced chronic rejection were $34(29.6 \%)$ and $6(40.0 \%)$, respectively, while $21(18.3 \%)$ and $7(46.7 \%)$ patients, respectively, experienced acute rejection. Although there were no statistically significant differences between the three groups $(P>0.05)$, both the chronic and acute rejection rates in Group 3 were higher than those in Groups 1 and 2 .

The patient outcomes, including graft failures and patient deaths, are shown in Table 2. There were no statistically significant differences in relation to any of these items between the groups $(P>0.05)$. However, a significantly higher incidence of any graft failure type was observed in Group 3, when compared with Group $1(P<0.05)$.

Incidence of NODAT based on pre-transplantation OGTT patterns

Seventeen $(6.9 \%)$ of the 248 patients in Group 1 developed hyperglycemia that necessitated transient antidiabetic therapy (transient NODAT), and six (2.4\%) patients developed permanent antiglycemic agent-dependent NODAT (permanent NODAT). Eleven $(9.6 \%)$ of the 115 patients in Group 2 developed transient NODAT, and seven (6.1\%) 
(a) $\mathrm{S}-\mathrm{Cr}(\mathrm{mg} / \mathrm{dl})$

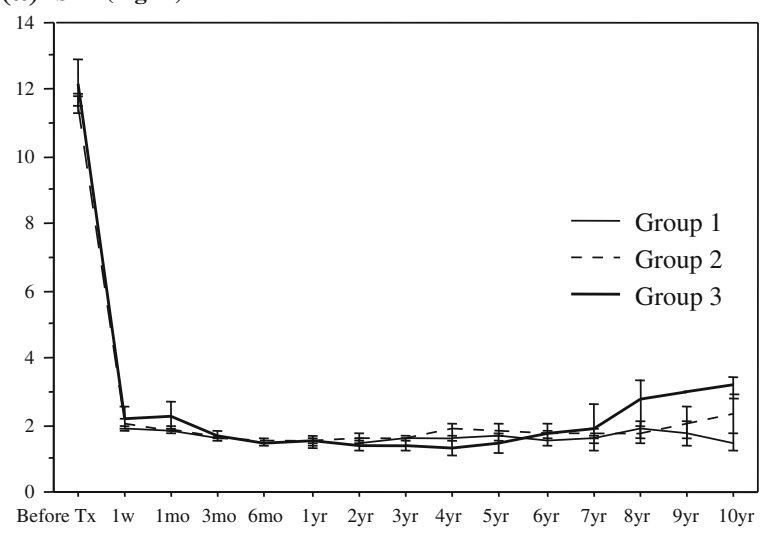

(c) $(\mathrm{mg} / \mathrm{dl})$

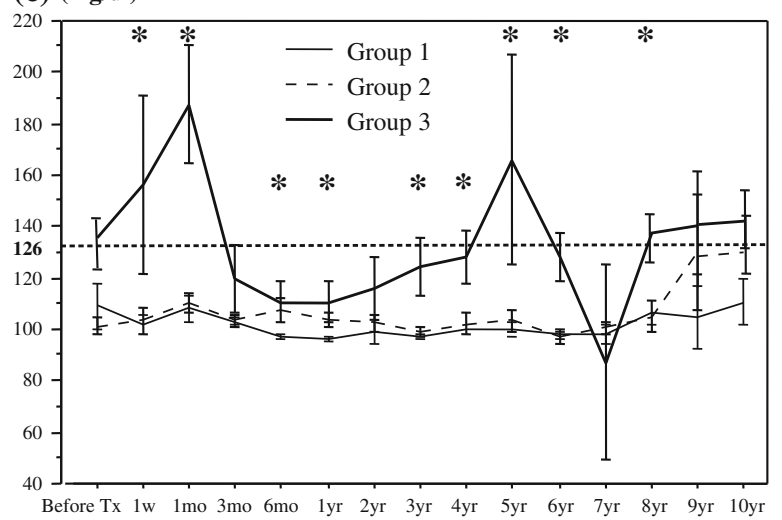

Fig. 1 Long-term sequential changes in serum creatinine (a), urinary protein (b), fasting blood glucose (c), and blood hemoglobin A1c after transplantation. The mean levels of s-Cr and urinary protein were maintained during the follow-up period in all groups. However, the fasting blood glucose levels in Groups 2 and 3 increased gradually and that of Group 3 was

developed permanent NODAT. Five $(33.3 \%)$ of the 15 patients in Group 3 developed transient NODAT, and three $(20.0 \%)$ developed permanent NODAT (Table 3). Interestingly, the remaining seven (46.7\%) patients in Group 3 did not develop transient or permanent NODAT.

There were no statistically significant differences between Group 1 and Group 2 with regard to the incidences of transient and permanent NODAT $(P>0.05)$, although the odds ratios, especially those for permanent NODAT, tended to be higher in Group $2(P>0.05)$. The incidences of transient and permanent NODAT in Group 3 were significantly higher than those in Groups 1 and 2. (b) (g/day)

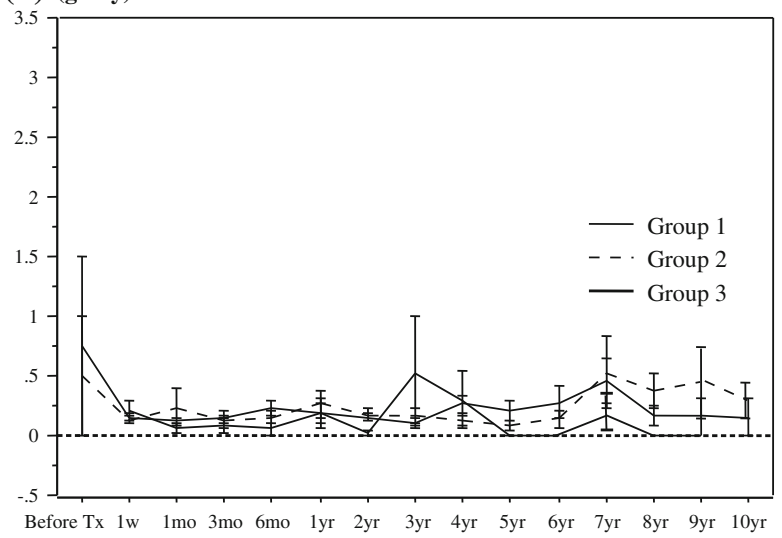

(d) $(\%)$

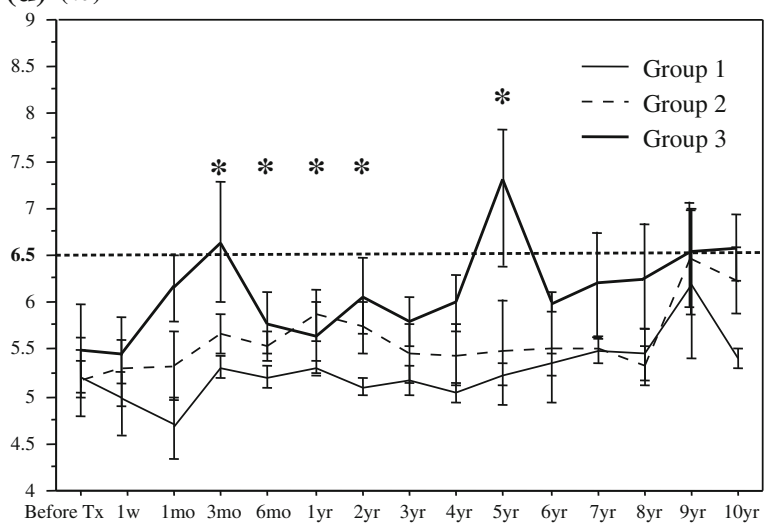

$>126 \mathrm{mg} / \mathrm{dl}$ for the last 3 years. Although HbA1c levels were higher $(>6.5 \%)$ for the last 2 years in Group 3, there were no statistically significant differences between the three groups $(P>0.05)$. Group 1, thin line; Group 2, dotted line; Group 3, thick line; *, statistically significant difference between groups $(P<0.05)$

Comparison of patients with non-diabetic, transient antidiabetic therapy-requiring and permanent antidiabetic therapy-requiring conditions

The characteristics of the recipients who developed NODAT are summarized in Table 4. The family history of DM was ascertained by strict inquiry before transplantation. The time for diagnosis of NODAT ranged from 14 to 326 days, with a mean of $40.9 \pm 6.38$ days post transplantation. During the follow-up period, blood glucose control improved and became normalized in 33 patients who were managed with dietary restriction alone, transient oral 
Fig. 2 a Kaplan-Meier estimates of patient survival. All groups demonstrated an excellent patient survival rate throughout the follow-up period. No statistically significant difference was detected between groups $(P>0.05)$. b KaplanMeier estimates of graft survival. Patients who exhibited the DM pattern (Group 3) showed a poorer allograft survival rate 2 years after transplantation $(P<0.05$; Group 3 versus Group 1 and 2); however, no statistically significant difference was detected between groups at 5-12 years after transplantation $(P>0.05)$
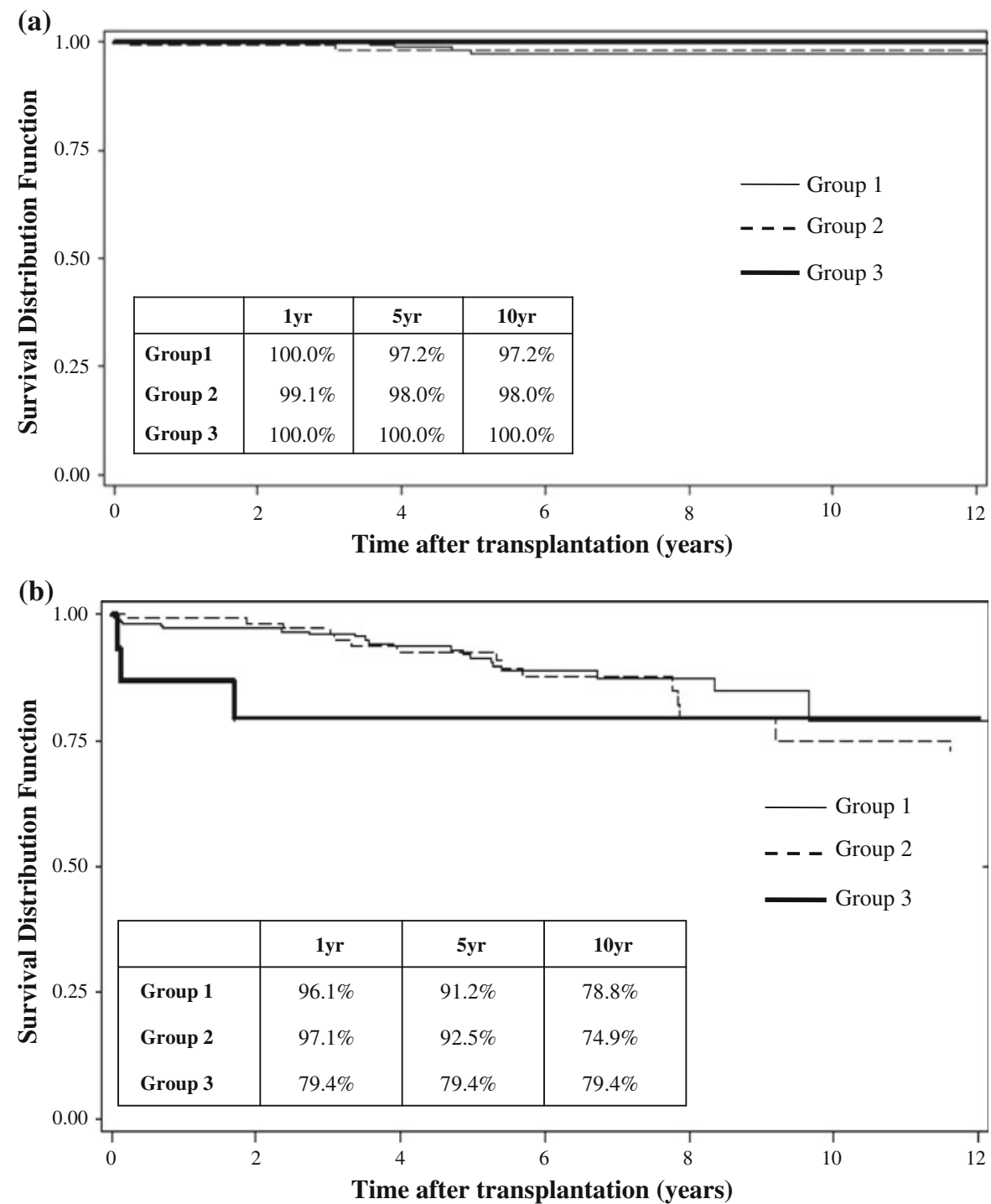

hypoglycemic agents or transient insulin administration, and who had a previous diagnosis of transient NODAT. At the end of the first year, diabetes persisted in 16 patients, four of whom were treated with a combination of insulin and oral antidiabetic medication and 12 of whom were treated with insulin alone; all 16 patients were considered to have permanent NODAT. Compared with the non-diabetic patients, there were no statistically significant differences in the clinical characteristics of the patients between the groups $(P>0.05)$, with the exception of family history of diabetes $(P<0.01)$. Family history was also significant in the multivariate analysis and adversely influenced NODAT. Although no statistical significance was found in this study, these transient and permanent NODAT recipients tended to have higher body mass index (BMI) values than did the non-diabetic recipients $(P>0.05)$.

\section{Discussion}

NODAT remains a serious complication of therapy with immunosuppressive drugs, in that it not only increases the risks of graft loss and mortality, but also predisposes the patients to all the complications of diabetes, including retinopathy and neuropathy. The diabetogenic effects of immunosuppressive therapies 
Table 2 Rates of rejection and patient outcomes a Statistical analysis between groups was performed using one-way ANOVA

\begin{tabular}{lcccc}
\hline & $\begin{array}{l}\text { Group 1 } \\
(n=248)\end{array}$ & $\begin{array}{l}\text { Group 2 } \\
(n=115)\end{array}$ & $\begin{array}{l}\text { Group 3 } \\
(n=15)\end{array}$ & $P$ value $^{\mathrm{a}}$ \\
\hline $\begin{array}{l}\text { Rejection episode } \\
\text { Chronic rejection }\end{array}$ & $83(33.5 \%)$ & $34(29.6 \%)$ & $6(40.0 \%)$ & 0.590 \\
$\quad \begin{array}{l}\text { Acute rejection } \\
\text { Long-term outcome }\end{array}$ & $52(21.0 \%)$ & $21(18.3 \%)$ & $7(46.7 \%)$ & 0.064 \\
Graft failure & $24(9.7 \%)$ & $15(12.8 \%)$ & $4(26.7 \%)$ & 0.065 \\
Death with function & $4(1.6 \%)$ & $2(1.7 \%)$ & & \\
Acute rejection & $4(1.6 \%)$ & & $1(6.7 \%)$ & \\
Chronic rejection & $11(4.4 \%)$ & $8(6.8 \%)$ & $1(6.7 \%)$ & \\
Non-compliance & $1(0.3 \%)$ & $1(0.9 \%)$ & & \\
Drug nephrotoxicity & $1(0.3 \%)$ & $1(0.9 \%)$ & & \\
Post-transplantation nephritis & $2(0.8 \%)$ & $3(2.6 \%)$ & $1(6.7 \%)$ & \\
$\quad$ Others & $1(0.4 \%)$ & & $1(6.7 \%)$ & \\
Death & $4(1.6 \%)$ & $2(1.7 \%)$ & & \\
\hline
\end{tabular}

Table 3 Incidence of NODAT

\begin{tabular}{|c|c|c|c|c|c|c|c|}
\hline \multicolumn{8}{|c|}{ NODAT patients } \\
\hline \multirow[t]{2}{*}{ Group } & \multirow[t]{2}{*}{ No. of patients } & \multicolumn{3}{|c|}{ Transient NODAT patients } & \multicolumn{3}{|c|}{ Permanent NODAT patients } \\
\hline & & Incidence & Odds ratio $(95 \% \mathrm{CI})$ & $P$ value & Incidence & Odds ratio $(95 \% \mathrm{CI})$ & $P$ value \\
\hline Group 1 & 248 & $17(6.9 \%)$ & 1.00 & & $6(2.4 \%)$ & 1.00 & \\
\hline Group 2 & 115 & $11(9.6 \%)$ & $1.71(0.80-3.66)$ & 1.160 & $7(6.1 \%)$ & $2.59(0.85-7.88)$ & 0.084 \\
\hline Group 3 & 15 & $5(33.3 \%)$ & $6.85(2.10-22.33)$ & $<0.001^{\mathrm{a}}$ & $3(20.0 \%)$ & $10.17(2.26-45.66)$ & $<0.001^{\mathrm{b}}$ \\
\hline
\end{tabular}

CI confidence interval

a,b Group 3 vs. Group 1: Chi-square

after organ transplantation are well-recognized [20]. However, since the definition of NODAT remains unclear, the reported incidences of NODAT have varied.

The criteria that we used in the present study for diagnosing DM in the post-transplantation period are the same as the 2003 International Consensus Guidelines [18] for the definition of DM in clinical practice. Until quite recently, the criteria used to diagnose NODAT varied among studies [20, 21]. Most definitions of NODAT in the literature are based on random glucose testing or fasting glucose levels $>140 \mathrm{mg} / \mathrm{dl}$.

Hjelmesaeth et al. [22] and Mathew et al. [21] reported NODAT and IGT rates of 18 and $31 \%$, and 21.4 and $24.1 \%$, respectively. In these previous studies, only patients with overt diabetes were included, and those with IFG/IGT were excluded. Unfortunately, we could not perform post-transplantation OGTT in the present study; thus, the incidence of NODAT reported here is likely underestimated.

Immunosuppressive agents that have adverse effects on glucose tolerance include corticosteroids, cyclosporine, and in particular, FK. Several reports have shown an increased incidence of NODAT among transplant recipients receiving FK. Todo et al. [23] first described the association between NODAT and FK in a cohort of 121 liver transplant recipients, 10 of whom developed insulin-requiring NODAT after transplantation. Weir et al. [5] described a significantly higher incidence of NODAT among renal transplant recipients treated with FK (8.3-25.4\%), when compared to those treated with cyclosporine $(2.2-7.0 \%)$.

In addition, several risk factors predispose patients to developing NODAT, including increased age, a family history of diabetes, increased BMI (obesity), 
Table 4 Characteristics of non-diabetic patients and diabetic patients with transient or permanent NODAT, and multivariate analysis of risk factors for the development of permanent NODAT

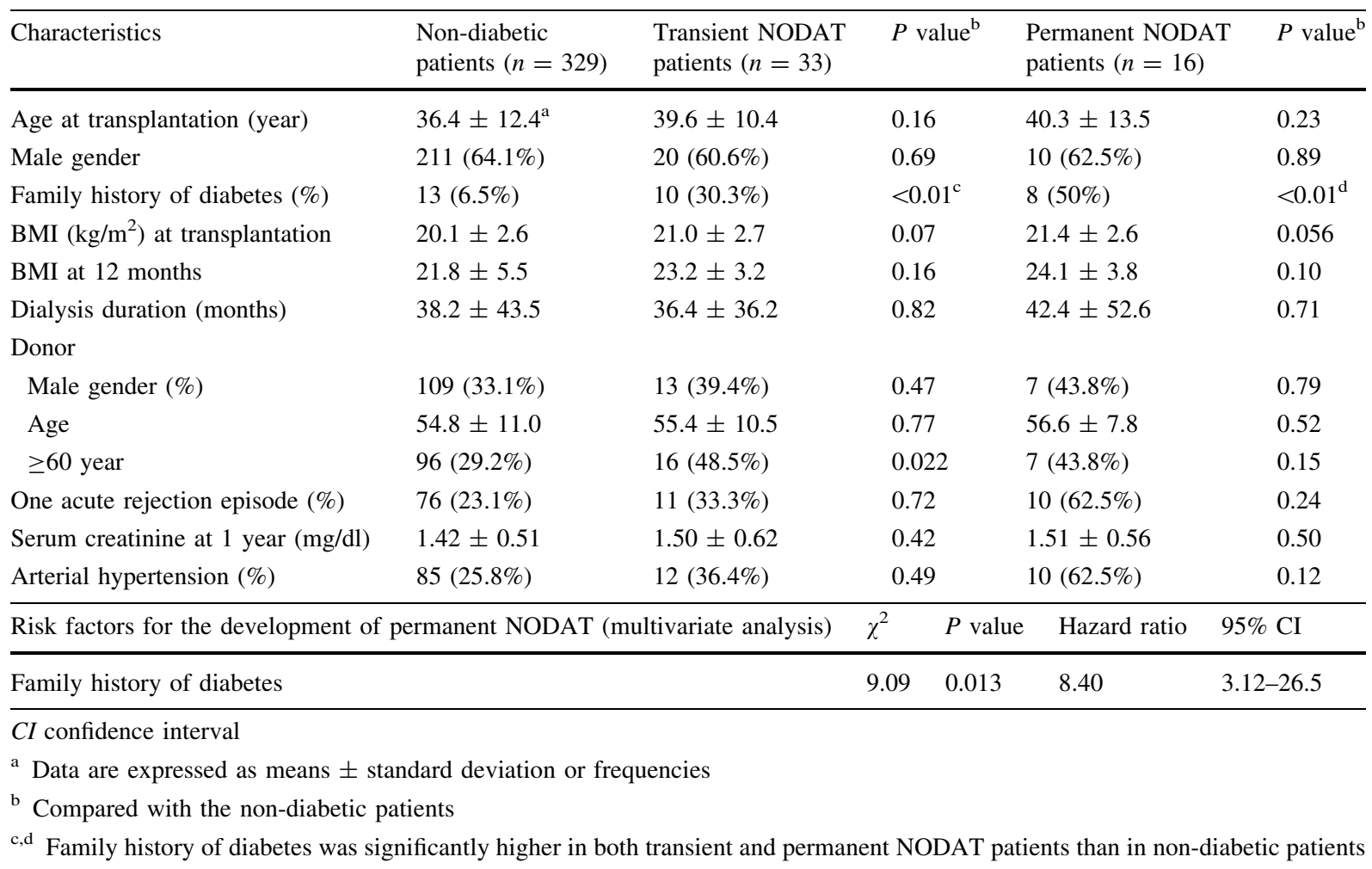

abnormal glucose tolerance pre-transplantation, and African or Hispanic descent [24, 25]. In the present study, only family history of diabetes was identified as a risk factor for NODAT development, which is dissimilar to previous reports.

As described earlier, we screened patients for diabetes risk factors, and all the recipients were evaluated by OGTT pre-transplantation. In addition, throughout the follow-up period, the patients underwent laboratory testing for fasting plasma glucose, urinary protein, and $\mathrm{HbAlc}$. The laboratory tests were monitored regularly in all the post-transplantation recipients twice weekly for 3 months, then weekly for 3 months, twice monthly for 1 year, and once per month over the next 10 years.

The management of NODAT was similar to that of diabetes in the non-transplant population and included dietary and lifestyle modifications. Patients who showed impaired glycemic control were promptly subjected to dietary restrictions; only those who were refractory to the dietary control intervention method were initiated on oral hypoglycemic agents. In selecting the oral agents and/or insulin, the medical profile of each individual was considered carefully. Corticosteroid exposure was limited as much as possible, and reducing the calcineurin inhibitor dosage was considered to be prudent.

Interestingly, seven of the 15 patients in Group 3 did not develop transient or permanent NODAT; instead, they showed a DM pattern in the pre-transplant OGTT. Although this mechanism could not be elucidated in this study, this result suggests that careful monitoring and management after transplantation can preserve the non-diabetic state of some recipients even if preoperative OGTT shows the IFG/IGT or DM pattern. In this study, the occurrence of NODAT had no effect on long-term patient and graft outcome. This result also contradicts the literature. Although there were significant differences in the numbers of transient and permanent NODAT patients in Group 3 (Table 3), such monitoring and management yielded excellent long-term graft survival and patient safety. 
In the present study, we followed up on patients who showed different glucose tolerance patterns in pre-transplantation OGTT, and we evaluated whether pre-operative OGTT is useful in predicting the occurrence of NODAT in FK-treated renal transplant recipients. It is widely known that end-stage renal disease and dialysis are associated with impaired glycemic control, which is caused by increased insulin resistance and impaired insulin secretion [21, 26]. Notably, before FK administration, 130 patients $(34.4 \%)$ showed impaired glycemic control, as revealed by the pre-transplantation OGTT. Thus, careful pre-transplantation screening and evaluation are required for predicting the occurrence of NODAT, and post-transplantation monitoring and management in consideration of results of pretransplantation OGTT may prevent progression to NODAT.

In conclusion, we determined that pre-operative OGTT is useful for predicting the occurrence of NODAT in renal transplant recipients who are receiving $\mathrm{FK}$ and who show the DM or IFG/IGT pattern in pre-operative OGTT. Even when preoperative OGTT shows impaired glycemic control, careful monitoring and management after transplantation may maintain the non-diabetic state.

Acknowledgments The authors thank Ms. Makiko Fujiwara and the staff at STAZ Institute for their assistance with data collection.

Financial disclosure All contributing authors have declared that there is no relationship with any companies and no conflict of interest in this study.

Open Access This article is distributed under the terms of the Creative Commons Attribution Noncommercial License which permits any noncommercial use, distribution, and reproduction in any medium, provided the original author(s) and source are credited.

\section{References}

1. Massy ZA, Kasiske BL (1996) Post-transplant hyperlipidemia: mechanisms and management. J Am Soc Nephrol 7: 971-977

2. Aakhus S, Dahl K, Wideroe TE (1999) Cardiovascular morbidity and risk factors in renal transplant patients. Nephrol Dial Transplant 14:648-654

3. Kasiske BL (2000) Cardiovascular disease after renal transplantation. Semin Nephrol 20:176-187
4. Jindal RM, Sidner RA, Milgrom ML (1997) Post-transplant diabetes mellitus. The role of immunosuppression. Drug Saf 16:242-257

5. Weir MR, Fink JC (1999) Risk for post transplant diabetes mellitus with current immunosuppressive medications. Am J Kidney Dis 34:1-13

6. Krentz AJ, Dmitrewski J, Mayer D, Nattrass M (1995) Effects of immunosuppressive agents on glucose metabolism. Clin Immunother 4:103-123

7. Pirsch JD, Miller J, Deierhoi MH, Vincenti F, Filo RS (1997) A comparison of tacrolimus and cyclosporine for immuno-suppression after cadaveric renal transplantation. FK506 Kidney Transplant Study Group. Transplantation 63:977-983

8. Mayer AD, Dmitrewski J, Squifflet JP, Besse T, Grabensee B, Klein B et al (1997) Multicenter randomized trial comparing tacrolimus (FK506) and cyclosporine in the prevention of renal allograft rejection: a report of the European tacrolimus Multicenter Renal Study Group. Transplantation 64:436-443

9. Knoll GA, Bell RC (1999) Tacrolimus versus cyclosporin for immunosuppression in renal transplantation: metaanalysis of randomized trials. Br Med J 318:1104-1107

10. Van Duijnhoven EM, Boots JMM, Christiaans MHL, Wolffenbuttel BHR, van Hooff JP (2001) Influence of tacrolimus on glucose metabolism before and after renal transplantation: a prospective study. J Am Soc Nephrology 12:583-588

11. Nam JH, Mun JI, Kim SI, Kang SW, Choi KH, Park K et al (2001) $\beta$-cell dysfunction rather than insulin resistance is the main contributing factor for development of postrenal transplantation diabetes mellitus. Transplantation 71:14171423

12. Ekstrand A, Ahonen J, Gronhagen-Riska C, Groop L (1989) Mechanisms of insulin resistance after kidney transplantation. Transplantation 48:563-568

13. Fivush B, Green OC, Porter CC, Balfe JW, O'Regan S, Gahl WA (1987) Pancreatic endocrine insufficiency in post transplant cystinosis. Am J Dis Child 141:1087-1108

14. Filler G, Amendt P, von Bredow MA, Rohde W, Ehrich JHH (1998) Slowly deteriorating insulin secretion and C-peptide production characterizes diabetes mellitus in infantile cystinosis. Eur J Pediatr 157:738-742

15. Schmitz O, Orskov L, Lund S, Moller N, Christiansen JS, Orskov H (1993) Glucose metabolism in chronic renal failure with reference to $\mathrm{GH}$ treatment of uremic children. J Pediatr Endocrinol 6:53-55

16. Tanabe K, Tokumoto T, Ishida $\mathrm{H}$ et al (2004) Excellent outcome of $\mathrm{ABO}$ incompatible living kidney transplantation under pretransplantation immunosuppression with tacrolimus, mycophenolate mofetil, and steroid. Transplant Proc 36:2175-2177

17. Ishida H, Miyamoto N, Shirakawa H et al (2007) Evaluation of immunosuppressive regimens in ABO-incompatible living kidney transplantation-single center analysis. Am J Transplant 7:825-831

18. Davidson J, Wilkinson A, Dantal J et al. (2003) New-onset diabetes after transplantation: 2003 International Consensus Guidelines. In: Proceedings of an international expert panel meeting. Barcelona, Spain, February 19, 2003. Transplantation 75(suppl): SS3 
19. Racusen LC, Solez K, Colvin RB et al (1999) The Banff 97 working classification of renal allograft pathology. Kidney Int 55:713-723

20. Scantlebury V, Shapiro R, Fung J et al (1991) New onset of diabetes in FK506 vs cyclosporine-treated kidney transplant recipients. Transplant Proc 23:3160-3170

21. Mathew JT, Rao M, Job V et al (2003) Post-transplant hyperglycaemia: a study of risk factors. Nephrol Dial Transplant 18:164-171

22. Hjelmesaeth J, Hartmann A, Kofstad J et al (1997) Glucose intolerance after renal transplantation depends upon prednisolone dose and recipient age. Transplantation 64:979

23. Todo S, Fung JJ, Starzl TE et al (1990) Liver, kidney, and thoracic organ transplantation under FK 506. Ann Surg 212:295
24. Suga A, Kishi Y, Fujikawa Y et al (2003) Diabetes mellitus after renal transplantation under tacrolimus-based immunosuppression. Transplant Proc 35:263-265

25. Sezer S, Bilgic A, Uyar M, Arat Z, Ozdemir FN, Haberal M (2006) Risk factors for development of posttransplant diabetes mellitus in renal recipients. Transplant Proc 38: 529-532

26. Kuypers DR, Claes K, Bammens B, Evenepoel P, Vanrenterghem Y (2008) Early clinical assessment of glucose metabolism in renal allograft recipients: diagnosis and prediction of post transplantation diabetes mellitus (PTDM). Nephrol Dial Transpl 23:2033-2042 